Jurnal Media Keperawatan: Politeknik Kesehatan Makassar

Vol. 08 No. 022017

e-issn : 2622-0148, p-issn : 2087-0035

\title{
HUBUNGAN DUKUNGAN KELUARGA DENGAN MOTIVASI DALAM MENGONTROL KADAR GULA DARAH PADA PENDERITA DIABETES MELITUS DI WILAYAH KERJA PUSKESMAS PAMPANG KECAMATAN PANAKKUKANG KOTA MAKASSAR
}

\author{
Family Support Relationship With Motivation In Control Drinking Blood Sugar To Patients Diabetes Melitus At \\ Pampang Public Health Center Panakkukang of Makassar City
}

\author{
Maryati Tombokan', Sukma Saini², Masdiana AR ${ }^{3}$, Muh Rezki Nurfajar Azis ${ }^{4}$ \\ Poltekkes Kemenkes Makassar \\ Program Studi D.IV Keperawatan \\ Email : nurfajarazism@gmail.com \\ No. Telp : 082193037208
}

\begin{abstract}
Diabetes Mellitus is a chronic metabolic disorder disease characterized by elevated blood glucose, caused by an imbalance between supply and insulin requirement. Diabetics are at risk for complications. These complications can be prevented by controlling blood glucose levels of diabetics through the implementation of four pillars of DM management, including meal planning, physical exercise, antidiabetic drugs and health education Control of blood sugar levels in patients DM is not enough to avoid complications but it requires the support of the family in motivating patients with diabetes mellitus to control blood sugar. Purpose: This research is to know the relationship between family support with motivation in controlling blood sugar level in Diabetes Mellitus patient. Method: This research is analytic descriptive with cross sectional design. The sampling technique used is total sampling with 30 respondents. The data were collected by using questionnaires. Data analysis using Chi Square test with significance level $\alpha=$ 0,05. Result: Based on statistical test result using Chi Square got $p$-value value 0,01 $(p<0,05)$. Conclusion: There is a significant correlation between family support and motivation in controlling blood glucose level in diabetes mellitus patient in Pampang Puskesmas, Panakkukang Sub-district, Makassar City.
\end{abstract}

Keywords: Family Support, Motivation, Diabetes Mellitus

\section{ABSTRAK}

Diabetes Melitus merupakan penyakit gangguan metabolisme kronis yang ditandai peningkatan glukosa darah, disebabkan karena ketidakseimbangan antara suplai dan kebutuhan insulin. Penderita DM berisiko mengalami komplikasi. Komplikasi tersebut dapat dicegah dengan mengendalikan kadar glukosa darah diabetesi melalui pelaksanaan empat pilar pengelolaan DM, diantaranya perencanaan makan, latihan jasmani, obat antidiabetik dan pendidikan kesehatan. Pengendalian kadar gula darah pada pasien DM tersebut belum cukup untuk menghindari terjadinya komplikasi akan tetapi diperlukan adanya dukungan dari keluarga dalam memotivasi penderita DM untuk melakukan pengontrol gula darah. Tujuan: penelitian ini ialah untuk mengetahui hubungan antara dukungan keluarga dengan motivasi dalam mengontrol kadar gula darah pada penderita Diabetes Melitus. Metode: Penelitian ini bersifat deskriptif analitik dengan desain cross sectional. Teknik sampling yang digunakan ialah total sampling dengan jumlah responden sebanyak 30 orang. Pengumpulan data dilakukan dengan menggunakan kuesioner. Analisa data menggunakan uji Chi Square dengan tingkat kemaknaan $a=0,05$. Hasil: Berdasarkan hasil uji statistik menggunakan risk didapatkan nilai $p$-value $0,01(p<0,05)$. Kesimpulan: Terdapat hubungan yang bermakna dukungan keluarga dengan motivasi dalam mengontrol kadar gula darah pada penderita diabetes melitus di wilayah kerja Puskesmas Pampang Kecamatan Panakkukang Kota Makassar.

\section{Kata Kunci : Dukungan Keluarga, Motivasi, Diabetes Melitus, Kadar Gula Darah}

\section{PENDAHULUAN}

Kesehatan merupakan kondisi yang paling utama dalam menunjang aktivitas sehari-hari, oleh sebab itu diperlukan langkah-langkah yang konkret dalam upaya penanganan dalam rangka mempertahankan kesehatan yang optimal. Upaya dalam menjaga kesehatan bukan suatu hal yang mudah, apalagi ancaman kesehatan di era sekaran gini dapat terjadi karena infeksi menular atau penyakit tidak menular (PTM). Salah satu masalah penyakit tidak menular yang berdampak pada produktifitas masyarakat dan kualitas hidup yaitu Diabetes Melitus (DM).

Menurut Tarwoto,dkk (2016) Diabetes Melitus merupakan penyakit gangguan metabolisme kronis yang ditandai dengan peningkatan glukosa darah (hiperglikemia), disebabkan karena ketidakseimbangan antara suplai dan kebutuhan 
Jurnal Media Keperawatan: Politeknik Kesehatan Makassar

Vol. 08 No. 022017

e-issn : 2622-0148, p-issn : 2087-0035

insulin. Insulin dalam tubuh dibutuhkan untuk memfasilitasi masuknya glukosa dalam sel agar dapat digunakan untuk metabolisme dan pertumbuhan sel. Berkurang atau tidak adanya insulin menjadikan glukosa tertahan di dalam darah dan menimbulkan peningkatan gula darah, sementara sel menjadi kekurangan glukosa yang sangat dibutuhkan dalam kelangsungan dan fungsi sel. Berdasarkan Angka kejadian DM di dunia dari tahun ke tahun menunjukkan adanya peningkatan. Berdasarkan data dari International Diabetes Federation (IDF 2017) jumlah penderita DM sebanyak 387 juta jiwa di tahun 2014 meningkat menjadi 424,9 juta jiwa di tahun 2017 dan diperkirakan akan bertambah menjadi 628,6 juta jiwa pada tahun 2045. Menurut Estimasi data International Diabetes Federation (IDF) dari hasil survey 2017 Asia tenggara menempati urutan ke-3 setelah Amerika Utara dan Afrika Utara dengan jumlah penderita Diabetes Melitus (DM) yaitu 8,5\% terjadi pada usia 20-29 tahun.

Menurut hasil Riskesdas Tahun 2013 Prevalensi diabetes di Sulawesi Selatan yang didiagnosis dokter sebesar 1,6 persen. DM yang didiagnosis dokter atau berdasarkan gejala sebesar 3,4 persen. Berdasarkan data dari Dinas Kesehatan Kota Makassar, angka kejadian penyakit diabetes melitus pada tahun 2011 yaitu 5700 kasus. Pada tahun 2012 angka kejadian kasus DM meningkat menjadi 14.067 kasus, tahun 2013 menjadi 14.604 kasus dan semakin meningkat di tahun 2014 menjadi 21.452 kasus (Dinkes Kota Makassar, 2015).

Diabetes melitus apabila jika tidak dikelola dengan baik akan mengakibatkan terjadinya berbagai penyakit menahun, seperti penyakit serebrovaskuler, penyakit jantung koroner, penyakit pembuluh darah tungkai, penyakit pada mata, ginjal maupun syaraf (Price \& Wilson, 2006). Studi penelitian telah membuktikan bahwa pasien Diabetes melitus yang melakukan kontrol kadar gula darah secara teratur memiliki kualitas hidup yang baik dan juga memiliki risiko komplikasi yang lebih rendah (Mcculloch, 2009). Komplikasi dari DM sendiri dapat menimbulkan kematian maupun kecacatan, sehingga perlu adanya pengendalian kadar gula darah. Pengendalian kadar gula darah meliputi diet makan, olahraga, upaya pengobatan dan kontrol gula darah. Kontrol gula darah berguna untuk menghindari kejadian komplikasi (Fox dan Kilvert, 2010).

Pengendalian kadar gula darah pada pasien DM tersebut belum cukup untukmenghindari terjadinya komplikasi akan tetapi diperlukan adanya dukungan dari keluarga dalam memotivasi penderita DM untuk melakukan pengontrol gula darah.

Dukungan keluarga merupakan indikator kuat yang dapat memberikan suatu dampak positif terhadap perawatan diri pada pasien dengan diabetes (Hensarling, 2009). Dukungan keluarga yang bersifat positif dapat meningkatkan meliputi motivasi penderita

dalam kepatuhan mengatur pola diet dan kontrol kadar gula darah.

Motivasi penderita untuk perawatan DM dapat dimulai pada diri sendiri atau dari luar seperti dukungan dari orang-orang terdekat atau keluarga dan tenaga kesehatan. Tujuannya agar penderita diabetes dapat mengontrolkan kadar gula darah sehingga tidak menimbulkan komplikasi penyakit yang berkelanjutan (Mahendra, 2008). Hal ini sejalan dengan peran perawat sebagai edukator sangat penting dalam memberikan informasi kepada pasien mengenai pentingnya melakukan kontrol gula darah dan memotivasi pasien agar melakukan kontrol gula darah secara rutin agar dapat dikendalikan (Mahendra, 2008).

Berdasakan data yang diperoleh dari Puskesmas Pampang Kota Makassar yang tercatat melakukan kujungan selama pada bulan April tahun 2018 sebanyak 32 orang yang menjadi peserta prolanis.

Penelitian yang dilakukan oleh Saputra (2015) menyatakan Dukungan keluarga pasien dengan diabetes mellitus tipe 2 untuk kontrol gula darah pada kedua kategori sebanyak $60 \%$ dan cukup sebanyak $40 \%$. Motivasi kerabat pasien dengan diabetes melitus tipe 2 yang memiliki motivasi untuk mengontrol gula darah pada keduakategori sebanyak 86,7\%, cukup sebanyak $10 \%$ dan kurang oleh $3,3 \%$. Ada hubungan yang signifikan antara dukungan keluarga dan motivasi pasien pengendalian gula darah Diabetes mellitus tipe 2. Ada hubungan antara dukungan keluarga dan motivasi kontrol gula darah pasien pada tipe 2.

Berdasarkan dari hal-hal diatas, maka peneliti tertarik untuk melakukan penelitian mengenai hubungan dukungan keluarga dengan motivasi klien dalam menengontrol kadar gula darah pada penderita DM pada Puskesmas Pampang Kota Makassar.

\section{METODE PENELITIAN}

Jenis penelitian ini bersifat deskriptif analitik menggunakan desain cross sectional yaitu variabel independen dukungan keluarga dan variabel dependen motivasi mrngontrol kadar gula darah pada penderita Diabetes Melitus di wilayah kerja Puskesmas Pampang Kecamatan Panakkukang Kota Makassar. Penelitian ini dilakukan di wilayah kerja Puskesmas Pampang Kecamatan Panakkukang Kota Makassar. Waktu pengumpulan serta analisa data dilakukan pada bulan April - Juni 2018.

Populasi dalam penelitian ini adalah seluruh pasien DM yang berkunjung di wilayah kerja Puskesmas Pampang Kecamatan Panakkukang Kota Makassar seluruh pasien DM yang terdata sebagai peserta prolanis yang rutin melakukan kujungan di wilayah kerja Puskesmas Pampang Kecamatan Panakukkang Kota Makassar sebanyak 31 orang selama bulan April. Teknik pengambilan sampel dalam penelitian ini yaitu dengan teknik total sampling. 
Jurnal Media Keperawatan: Politeknik Kesehatan Makassar

Vol. 08 No. 022017

e-issn : 2622-0148, p-issn : 2087-0035

Instrumen penelitian ini menggunakan kuesioner yang terdiri dari kuesioner karakteristik demografi responden dan kuesioner penilaian dukungan keluarga serta tingkat motivasi responden dalam mengontrol kadar gula darah.

Kuisioner dukungan keluarga sebanyak 20 pertanyaan yang mencakup dimensi informasi terdiri dari 5 item (pernyataan nomor 1-5), dimensi penghargaan terdiri dari 5 item (pernyataan nomor 6 10), dimensi instrumen terdiri dari 5 item (pernyataan nomor 11-15), dan dimensi emosional terdiri dari 5 item (pernyataan nomor 16-20).

Kuesioner motivasi diadopsi dari sujana (2012) terdiri dari 10 pertanyaan dengan menggunakan skala likert

Analisa data menggunakan analisis univariate dan analisis bevariate. Analisis bevariate melalui uji statistik yaitu dengan menggunakan uji chi-square.

\section{HASIL}

1. Distribusi karakteristik responden

Tabel 1. Distribusi responden berdasarkan umur Di Wilayah KerjaPuskesmas PampangKecamatan Panakkukang Kota Makassar

\begin{tabular}{ccc}
\hline Umur & $\begin{array}{c}\text { Frekuensi } \\
\text { (f) }\end{array}$ & $\begin{array}{c}\text { Persenta } \\
\text { se (\%) }\end{array}$ \\
\hline 36-45 Tahun & 2 & 6,7 \\
46-55 Tahun & 8 & 26,7 \\
56-65 Tahun & 10 & 33,3 \\
> 65 Tahun & 10 & 33,3 \\
\hline Total & $\mathbf{3 0}$ & $\mathbf{1 0 0 , 0}$ \\
\hline
\end{tabular}

Sumber : Data Primer Mei 2018

Berdasarkan tabel 1 menunjukkan bahwa dari 30 responden penderita $\mathrm{DM}$, sebagian besar berada pada rentang umur 56-65 tahun dan $>65$ tahun yakni masing-masing 10 orang $(33,3 \%)$. sedangkan paling sedikit pada rentang umur 36 40 tahun yakni sebanyak2 orang $(6,7 \%)$.

Tabel 2 Distribusi responden berdasarkan jenis kelamin Di Wilayah Kerja Puskesmas PampangKecamatan Panakkukang Kota Makassar

\begin{tabular}{ccc}
\hline Jenis Kelamin & $\begin{array}{c}\text { Frekuensi } \\
\text { (f) }\end{array}$ & $\begin{array}{c}\text { Persentase } \\
(\%)\end{array}$ \\
\hline Laki - Laki & 7 & 23,3 \\
Perempuan & 23 & 76,7 \\
\hline Total & $\mathbf{3 0}$ & $\mathbf{1 0 0 , 0}$ \\
\hline
\end{tabular}

Sumber : Data Primer Mei 2018

Tabel 2 menunjukkan sebagian besar penderita DM berjenis kelamin perempuan, yaitu sebanyak 23 orang $(76,7 \%)$ sedangkan berjenis kelamin laki-laki, hanya 7 orang $(23,3 \%)$.
Tabel 3 Distribusi responden berdasarkan Tingkat Pendidikan Di Wilayah Kerja Puskesmas Pampang Kecamatan Panakkukang Kota Makassar

\begin{tabular}{ccc}
\hline Pendidikan & $\begin{array}{c}\text { Frekuensi } \\
\text { (f) }\end{array}$ & $\begin{array}{c}\text { Persentase } \\
(\%)\end{array}$ \\
\hline SD & 1 & $3,3 \%$ \\
SMP & 2 & $6,7 \%$ \\
SMA & 25 & $83,3 \%$ \\
Perguruan & 2 & $6,7 \%$ \\
Tinggi & 20 & $\mathbf{1 0 0 , 0} \%$ \\
\hline Total & $\mathbf{2 0}$
\end{tabular}

Sumber : Data Primer Mei 2018

Data dari tabel 3 menunjukkan sebagian besar penderita DM merupakan lulusan SMA sebanyak 25 orang $(83,3)$ sedangkan lulusan SD hanya sebanyak 1 orang $(3,3 \%)$.

Tabel 4 Distribusi responden berdasarkan lama menderita DM Di Wilayah Kerja Puskesmas Pampang Kecamatan Panakkukang Kota Makassar

\begin{tabular}{ccc}
\hline Komplikasi & $\begin{array}{c}\text { Frekuensi } \\
\text { (f) }\end{array}$ & $\begin{array}{c}\text { Persentase } \\
(\%)\end{array}$ \\
\hline <5Tahun & 12 & $40,0 \%$ \\
25Tahun & 18 & $60,0 \%$ \\
\hline Total & $\mathbf{3 0}$ & $\mathbf{1 0 0 , 0} \%$ \\
\hline Sumber : Data Primer Mei 2018
\end{tabular}

Dari tabel 4 dapat diketahui bahwa sebagian penderita DM telah selama $\geq 5$ Tahun sebanyak 18 orang $(60,0 \%)$ dan sedangkan yang menderita DM selama $<5$ Tahun sebanyak 12 orang $(40,0 \%)$.

\section{Analisis Univariate}

Tabel 5. Distribusi Dukungan keluarga penderita Di Wilayah Kerja Puskesmas Pampang Kecamatan Panakkukang Kota Makassar

\begin{tabular}{ccc}
\hline $\begin{array}{c}\text { Dukungan } \\
\text { Keluarga }\end{array}$ & $\begin{array}{c}\text { Frekuensi } \\
\text { (f) }\end{array}$ & $\begin{array}{c}\text { Persentase } \\
(\%)\end{array}$ \\
\hline Baik & 23 & $76,7 \%$ \\
Kurang & 7 & $23,3 \%$ \\
\hline Total & $\mathbf{3 0}$ & $\mathbf{1 0 0 , 0} \%$ \\
\hline Sumber : Data Primer Mei 2018 &
\end{tabular}

Data dari tabel 5 menunjukkan bahwa keluarga memberikan dukungan pada penderita DMsebanyak 23 orang $(76,7 \%)$, sedangkan keluarga yang kurang mendukung pada penderita DMsebanyak 7 orang $(23,3 \%)$. 
Jurnal Media Keperawatan: Politeknik Kesehatan Makassar

Vol. 08 No. 022017

e-issn : 2622-0148, p-issn : 2087-0035

Tabel 6. Distribusi Dukungan Keluarga Penderita DM Berdasarkan Jenis Dukungan Keluarga Di Wilayah Kerja Puskesmas Pampang Kecamatan Panakkukang Kota Makassar

\begin{tabular}{|c|c|c|c|}
\hline \multicolumn{2}{|c|}{ Dukungan Keluarga } & $\begin{array}{c}\text { Frekuensi } \\
(\mathrm{f})\end{array}$ & $\begin{array}{c}\text { Persentase } \\
(\%)\end{array}$ \\
\hline \multirow{2}{*}{$\begin{array}{c}\text { Dimensi } \\
\text { Informasi }\end{array}$} & Baik & 20 & 66,7 \\
\cline { 2 - 4 } & Kurang & 10 & 33,3 \\
\hline Dimensi & Baik & 22 & 73,3 \\
\cline { 2 - 4 } Penilaian & Kurang & 8 & 26,7 \\
\hline Dimensi & Baik & 27 & 90 \\
\cline { 2 - 4 } Instrumen & Kurang & 3 & 10 \\
\hline Dimensi & Baik & 25 & 83,3 \\
\cline { 2 - 4 } Emosional & Kurang & 5 & 16,7 \\
\hline
\end{tabular}

Sumber : Data Peimer Mei 2018

Data dari tabel 6 menunjukkan bahwa dari keempat dimensi dukungan keluarga, dominan responden mendapatkan dukungan keluarga yang baik pada dimensi intrumen yakni sebanyak 27 orang responden dan paling sedikit responden mendapatkan dukungan keluarga yang baik pada

\section{Analisis Bivariat}

Tabel 8. Analisa hubungan dukungan keluarga dengan motivasi dalam mengontrol kadar gula darah pada Penderita Diabetes MelitusPuskesmas PampangKecamatan Panakkukang Kota Makassar

\begin{tabular}{|c|c|c|c|c|c|c|c|c|}
\hline & \multicolumn{4}{|c|}{ Motivasi } & \multirow{2}{*}{\multicolumn{2}{|c|}{ Total }} & \multirow{3}{*}{$p$} \\
\hline & & \multicolumn{2}{|c|}{ Tinggi } & \multicolumn{2}{|c|}{ Rendah } & & & \\
\hline & & $\mathbf{N}$ & $\%$ & $\mathbf{N}$ & $\%$ & $\mathbf{N}$ & $\%$ & \\
\hline \multirow{2}{*}{$\begin{array}{c}\text { Dukungan } \\
\text { Keluarga }\end{array}$} & Baik & 23 & $88,5 \%$ & 0 & $0 \%$ & 23 & $77 \%$ & \multirow{3}{*}{0,01} \\
\hline & Kurang & 3 & $11,5 \%$ & 4 & $100,0 \%$ & 7 & $23 \%$ & \\
\hline \multicolumn{2}{|c|}{ Total } & 26 & $100 \%$ & 4 & 15 & 30 & $100 \%$ & \\
\hline
\end{tabular}

Sumber : Data Primer Mei 2018

Data dari tabel 8 menunjukkan yang sebagian besar penderita DM memiliki dukungan keluarga serta motivasi yang tinggi sebanyak 23 orang $(88,5 \%)$, sedangkan masih terdapat penderita DMmendapat dukungan keluarga kurang dengan motivasi yang tinggi sebanyak 3 orang $(11,5 \%)$, sedangkan dengan motivasi yang rendah sebanyak 4 orang (100\%).

Dari hasil uji Chi square diperoleh nilai $p=$ 0,01 yang menunjukkan bahwa nilai $p=0,01$ lebih kecil dari $(<)$ nilai $\alpha=0,05$, berarti $\mathrm{H} 1$ diterima dan HO ditolak. Maka dapat disimpulkan Ada Hubungan Dukungan Keluarga Dengan Motivasi Dalam Mengontrol Kadar Gula Darah Pada Penderita Diabetes Melitus Di Wilayah Kerja Puskesmas Pampang Kecamatan Panakkukang Kota Makassar.

\section{PEMBAHASAN}

Berdasarkan hasil pengelolaan data sesuai dengan hasil penelitian lapangan dan disesuaikan dengan tujuan penelitian yang hendak dicapai. Maka diperoleh dari analisis sebagai berikut:

1. Dukungan keluarga dimensi informasi yakni sebanyak 20 orang responden.

Tabel 7 Distribusi Motivasi mengontrol kadar gula darah pada penderita DM Puskesmas Mamajang Kec.Mamajang Kota Makassar

\begin{tabular}{ccc}
\hline Motivasi & $\begin{array}{c}\text { Frekuensi } \\
(\mathrm{f})\end{array}$ & $\begin{array}{c}\text { Persentase } \\
(\%)\end{array}$ \\
\hline Tinggi & 26 & $86.7 \%$ \\
Rendah & 4 & $13.3 \%$ \\
\hline Total & $\mathbf{3 0}$ & $\mathbf{1 0 0 , 0} \%$ \\
\hline
\end{tabular}

Sumber : Data Primer Mei 2018

Data dari tabel 7 menunjukkan bahwa responden yang memiliki motivasi tinggi untuk mengontrol kadar gula darah sebanyak 26 orang $(86,7 \%)$, sedangkan responden yang memiliki motivasi rendah untuk mengontrol kadar gula darah sebanyak 4 orang $(13,3 \%)$.
Berdasarkan penelitian yang telah dilakukan, dukungan keluarga terhadap keberhasilan mengontrol kadar gula darah menunjukkan sebagian besar keluarga memberikan dukungannya baik bersifat informasi (saran, nasehat informasi), penilaian (menghargai, umpak balik), emosional (perhatian, kasih sayang, empati) maupun instrumen (bantuan, tenaga, dana dan waktu). Ini menunjukkan bahwa keluarga responden senantiasa memberikan dukungan kepada responden dalam menghadapi penyakit yang diderita sehingga pasien bisa menerima kondisinya, menambah rasa percaya diri dan mau berobat dengan teratur yang untuk meningkatkan kualitas hidupnya dalam keberhasilan mengontrol kadar gula darah bisa tercapai dengan baik.

Hal ini sesuai dengan penelitian sebelumnya yang dilakukan Kosim, dkk (2016) di RS PKU Muhammadiyah Yogyakarta tahun 2016, responden rata-rata responden (85,0\%) mendapatkan dukungan keluarga baik. Penelitian tersebut juga menjelaskan bahwa keluarga berfungsi sebagai sumber energi yang 
Jurnal Media Keperawatan: Politeknik Kesehatan Makassar

Vol. 08 No. 022017

e-issn : 2622-0148, p-issn : 2087-0035

menentukan kebahagiaan, keluarga sebagai sosialisasi dalam memberikan informasi, nasehat, saran, pemenuhan kebutuhan ekonomi dan keluarga sebagai perawatan serta pemeliharaan kesehatan termasuk dalam melakukan olahraga. Dukungan keluarga merupakan indikator yang kuat yang dapat memberikan suatu dampak positif terhadap perawatan diri pada pasien dengan Diabetes (Hensarling, 2009).

2. Motivasi

Hasil penelitian didapatkan bahwa sebagian besar responden $(88,5 \%)$ memiliki motivasi yang tinggi dalam mengontrol kadar gula darah. Hal tersebut menunjukkan bahwa besarnya keinginan diri dalam mengontrol kadar gula darah dan menyadari betapa pentingnya untuk merubah perilaku hidup sehingga status kesehatan agar tetap terkontrol.

Peneliti berpendapat bahwa salah satu faktor yang mempengaruhi tingginya motivasi responden dalam mengontrol kadar glukosa darah ialah faktor keinginan dalam diri responden agar sembuh dari penyakitnya dan adanya dukungan yang diterima dari keluarganya, dimana dari 30 responden terdapat 23 responden yang mendapatkan dukungan baik dari keluarganya.

Hal diatas didukung oleh Nugroho (2012) yang dikutip dalam Sujana (2012) yang menyatakan bahwa motivasi penderita diabetes melitus dalam mengontrol kadar gula darah dipengaruhi oleh motivasi intrinsik berupa keinginan dari dalam diri penderita yang memiliki niat dan kesadaran yang tinggi untuk mengontrol kadar glukosa darah seperti keinginan untuk disiplin dalam diet, patuh dan teratur dalam latihan fisik, teratur dalam berobat atau terapi medis dan keinginan untuk meningkatkan pengetahuan tentang penyakitnya dan motivasi ekstrinsik yang datangnya dari luar diri sendiri seperti dukungan keluarga, teman dekat, tokoh masyarakat, dukungan ekonomi dan dukungan petugas kesehatan.

3. Hubungan dukungan keluarga dengan motivasi dalam mengontrol kadar gula darah

Berdasarkan hasil uji statistic dari hasil uji Chi Square diperoleh nilai $p=0,01$ lebih kecil $(<)$ nilai a 0,05 , artinya ada hubungan bermakna dukungan keluarga dengan motivasi dalam mengontrol kadar gula darah pada penderita Diabetes Melitus di wilayah kerja Puskesmas Pampang Kecamatan Panakkukang Kota Makassar.

Berdasarkan tabel diketahui bahwa sebagian besar responden yang dukungan keluarganya baik memiliki motivasi yang tinggi dalam mengontrol kadar glukosa darah. Menurut peneliti, hal tersebut terjadi karenadukungan dari keluarga baik berupa informasi, penghargaan, instrumen maupun emosional dapat mempengaruhi kenyamanan fisik maupun psikologi dalam meningkatkan rasa percaya diri, merasa berharga dan dicinta sehingga meningkatkan motivasi penderita DM dalam mengontrol kadar glukosa darah.

Hal diatas sejalan dengan Wardani dan Isfandiari (2014) yang dalam penelitiannya menyatakan bahwa dukungan keluarga sangat berpengaruh bagi pasien diabetes dalam melakukan pengendalian kadar glukosa darah.

Selain itu, sebagian besar responden telah menderita DM selama $\geq 5$ tahun dan sebagian besar telah berusia lanjut. Responden yang telah menderita $\mathrm{DM} \geq 5$ tahun cenderung merasa jenuh dengan penyakitnya dan motivasi dalam mengontrol kadar glukosa darahnya cenderung berkurang. Hal tersebut didukung oleh Bernal, dkk (2000) yang dikutip dalam Bertalina dan Purnama (2016) yangmenyatakan bahwa tingkat kepatuhan dengan durasi penyakit cenderung negatif, dimana semakin lama pasien menderita Diabetes Melitus, semakin kecil kemungkinan untuk menjadi patuh terhadap pengobatan dan pengontrolan kadar glukosa darah sehingga dukungan keluarga sangat dibutuhkan agar penderita DM tidak merasa jenuh dengan pengobatannya dan selalu termotivasi dalam mengontrol kadar glukosa darahnya.

Sedangkan responden yang berusia lanjut cenderung kurang mempunyai motivasi dalam mengontrol kadar glukosa darah dikarenakan berkurangnya kemampuan untuk menyerap pengetahuan dan berkurangnya daya ingat mengenai cara mengontrol kadar glukosa darah. Hal tersebut didukung oleh Santoso dan Andar (2009) yang menyatakan bahwa dengan bertambahnya usia, maka akan terjadi gangguan kognitif yang jelas terlihat pada daya ingat dan kecerdasan. Fungsi kognitif yang dimaksud ialah proses mental dalam memperoleh pengetahuan atau kemampuan kecerdasan, meliputi cara berpikir, daya ingat, pengertian, perencanaan dan pelaksanaan pengontrolan glukosa darah. Dengan demikian, dukungan keluarga baik dalam bentuk dukungan informasional, dukungan penilaian atau penghargaan, dukungan intrumental dan dukungan emosional sangat dibutuhkan dalam memantau dan membantu pelaksanaan pengontrolan glukosa darah responden lansia sehingga meningkatkan motivasi lansia dalam mengontrol kadar glukosa darahnya.

Secara statistik masih terdapat penderita DM yang mendapat dukungan yang kurang tetapi masih memiliki motivasi mengontrol kadar gula darah yang tinggi. Menurut peneliti, hal tersebut disebabkan karena faktor pendidikan dimana sebagian besar responden mempunyai tingkat pendidikan yang tinggi (SMA). Responden dengan pendidikan yang tinggi dapat menerima informasi 
Jurnal Media Keperawatan: Politeknik Kesehatan Makassar

Vol. 08 No. 022017

e-issn : 2622-0148, p-issn : 2087-0035

dengan baik dan dapat mengerti pentingnya mengontrol kadar glukosa darah secara rutin serta memiliki pengetahuan dalam merawat dirinya sendiri. Hal tersebut sejalan dengan yang dikemukakan oleh Notoadmodjo (2010) dikutip dalam Karomah (2015) bahwa semakin tinggi tingkat pendidikan seseorang, semakin mudah ia memahami hal baru dan menyelesaikan aneka persoalan yang berkaitan dengannya termasuk persoalan kadar glukosa darahnya yang tidak stabil sehingga meskipun dengan dukungan keluarga yang kurang, responden masih memiliki motivasi dalam mengontrol kadar glukosa darahnya.

\section{KESIMPULAN}

1. Sebagian besar responden $(88,5 \%)$ memiliki dukungan keluarga yang tinggi dalam mengontrol kadara gula darah pada penderita Diabetes Melitus diwilayah kerja Puskesmas Pampang Kecamatan Pampang Kota Makassar.

2. Sebagian besar responden $(88,5 \%)$ memiliki motivasi yang tinggi dalam mengontrol kadara gula darah pada penderita Diabetes Melitus diwilayah kerja Puskesmas Pampang Kecamatan Pampang Kota Makassar.

3. Ada hubungan yang bermakna dukungan keluarga dengan motivasi dalam mengontrol kadar gula darah pada penderita diabetes melitus di wilayah kerja Puskesmas Pampang Kecamatan
Panakkukang Kota Makassar, dengan nilai $p$ $(0,01)$ a $(0,05)$.

\section{SARAN}

1. Bagi peneliti selanjutnya diharapkan penelitian ini dapat digunakan sebagai dasar untuk mengembangkan penelitian selanjutannya yang berhubungan dengan dukungan keluarga dengan motivasi dalam mengontrol kadar gula darah dengan menggunakan desain dan jenis penelitian yang lainnya.

2. Bagi keluarga diharapkan dapat menjadi sumber informasi dan mendampingi anggota keluarga dengan diabetes mellitus, serta diharapkan dapat meningkatkan kesadaran bagi keluarga baik dukungan moril dan psikologi agar lebih memperhatikan aktivitas pengendalian kadar gula darah pada penderita.

3. Bagi penderita diharapkan agar selalu meningkatkan pengetahuan dan sikap penderita tentang penyakit DM dan dampaknya terhadap kesehatan.

4. Bagi puskesmas diharapkan dapat menjadikan bahan masukan management Puskesmas Pampang Kota Makassar dalam upaya memberikan pendidikan kesehatan berupa pemeriksaan gula darah secara rutin ke puskesmasdan meningkatkan program kerja puskesmas khususnya upaya preventif pada penderita DM.

\section{DAFTAR PUSTAKA}

ADA. (2018). Standards Of Medical Care In Diabetes. The Journal Of Clinical And Applied Research And Education , $1-150$.

Arda, D. (2016). Pengetahuan Perawat Tentang Penggunaan Insulin Pada Pasien. Jurnal Keperawatan , 922-929.

Bertalina, \& Purnama. (2016). Hubungan Lama Sakit, Pengetahuan, Motivasi Pasien dan Dukungan Keluarga dengan Kepatuhan Diet Pasien Diabetes Melitus. VII(2), 329-340.

Bilous, R., \& Donelly, R. (2014). Buku Pegangan Diabetes Edisi 4. Jakarta: Bumi Medika.

Brunner dan Suddarth. (2013). Keperawatan Medikal Bedah Edisi 12. Jakarta: EGC

Damayanti, S. (2015). Diabetes Melitus \& Penatalaksanaan Keperawatan. Yogyakarta: Nuha Medika.

Dewi, R. K. (2014). Diabetes Bukan Untuk Ditakuti. Jakarta: Fmedia.

Dimyanti, \& Mudjiono. (2006). Belajar dan Pembelajaran. Jakarta: Rineka Cipta.

Fox, C., \& Kilvert, A. (2010). Bersahabat Dengan Diabetes Tipe 2. Jakarta: Penebar Plus.

Friedman, M. (2010). Buku Ajar Keperatawan Keluarga : Riset, Teori, Dan Praktek Edisi 5. Jakarta : EGC.

Handayani, D., \& Rudijanto, A. (2015). Penatalaksanaan Gizi Pada Diabetes Melitus. Malang: Danar Wijaya.

Harnilawati. (2013). Konsep dan Proses Keperawatan Keluarga. Sulawesi Selatan: Pustaka As Salam.

Hasibuan, M. S. (2006). Manajemen Sumber Daya Manusia. Jakarta: Bumi Aksara .

IDF. (2017). Dipetik Februari 11, 2018, dari Online Version Of Diabetes Atlas Eight Edition : http://diabetesasia.org/content/diabetes_guidelines/IDF_guidelines.pdf

Karomah, H. (2015). Hubungan Pengetahuan Ibu Dalam Penerapan Toilet Training Pada Usia Toddler 18-36 Bulan Di PAUD MPA Daycare Bumi Telukjambe Karawang.

Kosim, M. N., Damayanti, S., \& Sucipto, A. (2016). Hubungan Dukungan Sosial Keluarga Dengan Kepatuhan Olahraga Pasien Diabetes Melitus Tipe 2 Di Kelompok Persadia RS PKU Muhammadiyah Yogyakarta.

Lemone, P., Burke, K. M., \& Bauldoff, G. (2016). Buku Ajar Keperawatan Medikal Bedah. Jakarta: EGC.

Lusiana, N., Andriyani, R., \& Megasari, M. (2015). Metodologi Penelitian Kebidanan. Yogyakarta: Deepublish.

Mahendra. (2008). Care Your Self Diabetes Mellitus. Jakarta: Penebar Plus. 
Jurnal Media Keperawatan: Politeknik Kesehatan Makassar

Vol. 08 No. 022017

e-issn : 2622-0148, p-issn : 2087-0035

McCulloch, D. (2009). Patient Information. Dipetik February 12, 2018, dari Self-Blood Glucose Monitoring In Diabetes Melitus: Http://www.uptodate.com/contents/patiens-information-self-blood-glucose-monitoring-in-diabetesmellitus

Notoatmodjo. (2015). Metodologi Penelitian Kesehatan. Jakarta: Rineka Cipta.

Price, S. A., \& Wilson, L. M. (2006). Patofisologi Konsep Klinis Proses-Proses Penyakit. Jakarta : EGC.

Ratumanan. (2002). Inovasi Pembelajaran. Surabaya: UNESA University Press.

Riskesdas. (2013). Dipetik Februari 12, 2018, dari Hasil Riset Kesehatan Dasar: http://www.depkes.go.id/resources/download/general/Hasil\%20Riskesdas\%202013.pdf

Rivai, V. (2006). Manajemen Sumber Daya Manusia untuk Perusahaan : Dari Terori Praktik. Jakarta: PT. Raja Grafindo Persada.

Rudjianto, A. (2014). Keterangan Ringkas Tentang Diabetes Melitus (Kencing Manis). Malang: DaNar Wijaya.

Rumahorbo, H. (2014). Mencegah Diabetes Melitus dengan Perubahan Gaya Hidup. Bogor : In Media.

Sardiman, A. (2007). Interaksi Motivasi \& Belajar Mengajar. Bandung: Rajawali Pers.

Santoso, \& Andar, I. (2009). Memahami Krisis Lanjut Usia. Jakarta: PT BPK Gunung Mulia.

Sujana. (2012). Hubungan Motivasi Penderita Diabetes Melitus Dengan Perilaku (Mengontrol) Kadar Gula Darah Di Puskesmas Panongan Kab. Majalengka.

Siyoto, S., \& Sodik, M. A. (2015). Dasar Metodologi Penelitian. Yogyakarta: Literasi Media Publishing.

Smeltzer, S., \& Bare, B. (2013). Buku Ajar Keperawatan Medikal Bedah. Jakarta: EGC.

Soegondo, S., Soewondo, P., \& Subekti, I. (2015). Penatalaksanaan Diabetes Terpadu Edisi Kedua. Jakarta: Balai Penerbit FKUI.

Tandra, H. (2017). Segala Sesuatu Yang Harus Anda Ketahui Tentang Diabetes. Jakarta: Pt Gramedia Pustaka Utama.

Tarwoto, dkk. (2016). Keperawatan Medikal Bedah Gangguan Sistem Endokrin.

Wardani, A. K., \& Isfandiari, M. A. (2014). Hubungan Dukungan Keluarga Dan Pengendalian Kadar Gula Darah Dengan Gejala Komplikasi Mikrovaskuler. 2(1), 1-1 